\title{
IDENTIFICAÇÃO E ANÁLISE DE ASPECTOS AMBIENTAIS EM ATIVIDADE DE CERÂMICA VERMELHA, PARAGOMINAS-PA
}

\author{
Lucimar Costa Pereira; Maria Renata da Rocha Xavier; Maycon Viana Balbino; Nayara do Socorro \\ Nascimento Farias; Lorena Saraiva Viana; Tulio Marcus Lima da Silva.
}

DOI: $10.4322 / 978-85-455202-1-4-19$

\section{INTRODUÇÃO}

Os materiais cerâmicos, em diversas formas de utilização, ainda continuam sendo aplicados, de maneira ampla, e são relacionados a um alto padrão de vida devido às características que os tornam superiores a outros insumos (NUNES, 2012). Em função de distintas características, tais como matérias-primas empregadas, propriedades e utilização dos produtos fabricados, os diversos segmentos que compõem o setor cerâmico, podem ser classificados em: cerâmica branca, de revestimento, vermelha, materiais refratários, isolantes térmicos, e outros. Nesse contexto, a cerâmica vermelha é caracterizada por apresentar produtos oriundos da argila ou misturas que contenham esse recurso, a partir de moldagem, secagem e queima da mesma. Em função desse fator vem a cor avermelhada que dá o nome do segmento (OLIVEIRA; MAGANHA, 2006).

A cor avermelhada da cerâmica vermelha caracteriza os produtos oriundos da mesma, representados por tijolos, blocos, telhas, tubos, lajes para forro, lajotas, vasos ornamentais, agregados leves de argila expandida entre outros. Quanto à matéria-prima utilizado no setor, a mesma consiste basicamente em argila comum, em que a massa é tipo monocomponente (somente argila) e pode ser denominada de simples ou natural. (SANTANA et al., 2008).

Em contexto nacional, um número significativo das empresas do setor de cerâmica vermelha é de gestão familiar tradicional, o que pode inferir que o conhecimento é obtido de maneira empírica. A partir desse método de obtenção de informações, é realizada a determinação da quantidade de água a ser acrescida à massa, verificação de necessidade ou não de adição de outros materiais (beneficiamento) ou até a mistura com outras argilas. Todo esse processo auxilia a forma como a massa se torna mais propícia para a aplicação do processo fabril do produto cerâmico e melhorar suas propriedades finais (VALE et al., 2006).

No Brasil, verificam-se grandes dificuldades de acesso e obtenção de dados estatísticos e indicadores de desempenho do setor de cerâmica vermelha, o que causa deficiência para que ocorra acompanhamento do crescimento e melhoramento de competitividade. Além deste fator, o segmento industrial apresenta uma série de complexidades, entre as principais os problemas ambientais e de qualidade dos produtos. É configurada como uma atividade de base, haja vista que possibilita à construção civil, de maneira geral, materiais simples e também sofisticados (SANTOS JUNIOR, et al., 2017).

Apesar de apresentar pontos positivos para o movimento da economia, a indústria de cerâmica vermelha, caracteriza-se como um dos tipos de atividades industriais que mais provocam problemáticas ambientais. No que tange ao ocasionamento de problemas ambientais, a comercialização e extração de matérias primas como a argila, água, lenha, produtos imperfeitos e emissões de particulados pós queima, são característicos desse tipo de atividade (KUASOSKI; DOLIVEIRA; SILVA, 2015).

Nesse contexto, os aspectos ambientais, tais como emissão de gases poluentes e ruído, e geração, principalmente de resíduos, estão presentes nas etapas referentes a extração de argila e produção de tijolos (SANTOS, 2017). De tal forma, verifica-se possibilidade de ocorrência de impactos ambientais que necessitam de medidas preventivas capazes de diminuírem os efeitos das problemáticas.

Nesse contexto, esta pesquisa objetivou identificar e analisar os principais aspectos ambientais e as possíveis problemáticas associadas a estes na fase de produção de tijolos no município de Paragominas. Além disso, a mesma buscou propor medidas de mitigação dos possíveis impactos ambientais relacionados com a atividade. 


\section{METODOLOGIA}

\section{CARACTERIZAÇÃO DO MUNICÍPIO}

O município de Paragominas - PA, parte central da mesorregião do Nordeste Paraense, localizado entre os paralelos de $2^{0} 38^{\prime}$ e $3^{0} 40^{\prime}$ de latitude sul e meridianos de $46^{0} 27^{\prime}$ e $48^{0} 50^{\prime}$ de longitude oeste de Greenwich, com uma população estimada em 2017, de 110.026 habitantes. O município está distante da região metropolitana de Belém $320 \mathrm{~km}$ e possui como principal via de comunicação e transporte a Rodovia BR-010, que o atravessa no sentido norte-sul (IBGE, 2010).

A população estimada para o município é de aproximadamente $19.342,254 \mathrm{~km}^{2}$. A vegetação é classificada, de maneira geral, como floresta equatorial densa (IBGE, 2010). A maior parte (95\%) do solo do município é do tipo latossolo amarelo distrófico, com alto grau de intemperismo, de característica profunda, ácida e elevado nível de alumínio. As bacias do rio Capim e Gurupi constituem a hidrografia do município, enquanto o relevo situa-se no Domínio Morfo-estrutural dos Planaltos em Sequência Sedimentares Não Dobradas e a topografia possui áreas que variam entre 50 e 200 metros de altura (BRASIL, 2009).

\section{CARACTERIZAÇÃO DO EMPREEDIMENTO}

O empreendimento trata-se de uma indústria de atividade de cerâmica voltada para a produção de tijolos. Esta, localiza-se entre as coordenadas geográficas $2^{\circ} 59^{\prime} 52.14^{\prime \prime} \mathrm{S}$ e $47^{\circ} 21^{\prime} 49.57^{\prime \prime} \mathrm{O}$, na região oeste da área urbana de Paragominas, no bairro Uraim (Figura 1). Possui como principal via de acesso (entrada e saída) as margens da rua Monte Líbano. A empresa é uma das primeiras do município na fabricação de Tijolos de 2, 4, 6 e 8 furos, tijolo maciço, tijolos semi-maciços e comongol. A produção é realizada a partir da argila branca (40\%) e vermelha (60\%), extraídas em propriedades rurais do proprietário da empresa.

Figura 1 - Mapa físico de localização do empreendimento analisado. Paragominas - PA.

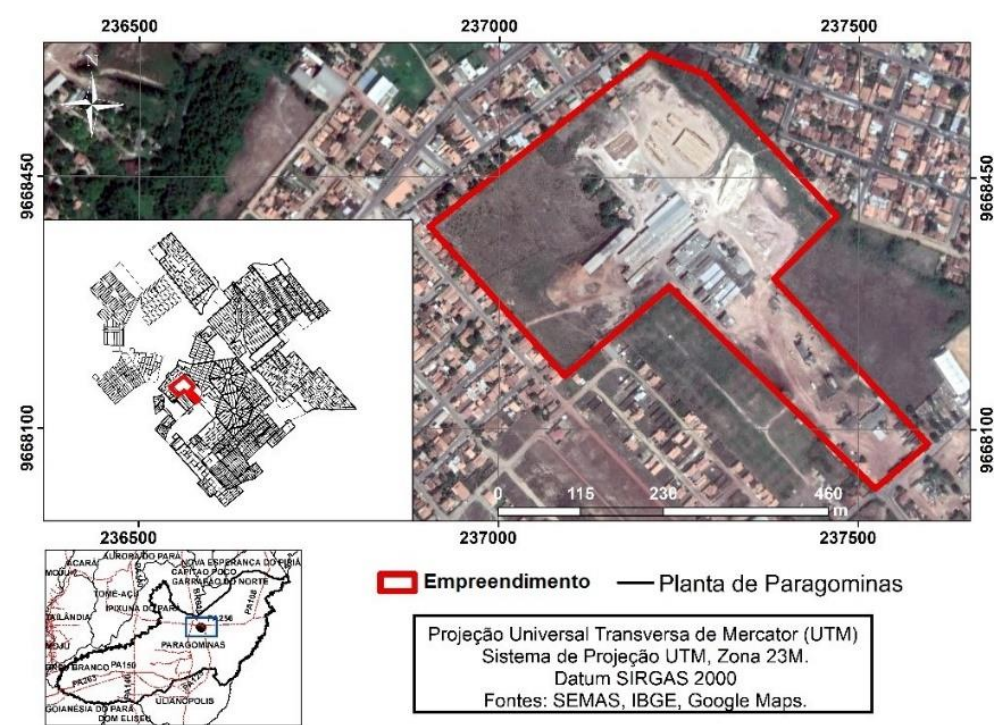

Fonte: autores (2018).

DESCRIÇÃO DO PROCESSO PRODUTIVO 
O processo produtivo do empreendimento apresenta uma sequência operacional, que se divide em: depósito de porções de argila no caixão alimentador, mistura, maromba, corte, secagem e queima. Na primeira etapa, a matéria-prima é depositada e transportada via esteira até a área de mistura. Nesta, ocorre a homogeneização completa da água com a argila e o material resultante é direcionado a Maromba. A partir de tal, o bloco a ser produzido é moldado por boquilhas e cortado automaticamente conforme tamanhos pré-estabelecidos, seguindo de inspeções com a finalidade de retirar as eventuais peças defeituosas.

Já na secagem, os tijolos ficam expostos à luz solar em um período de 20 a 35 dias. Esta etapa, de acordo com Leite et al. (2016), consiste em um processo necessário para evitar trincas no produto durante a realização da queima, que ocorre em dois fornos e geralmente dura 36 horas. Os fornos são alimentados com resíduos de serraria (serragem e pedaços de madeira). Nestes, os tijolos são empilhados e enfileirados.

Os fornos operam com uma temperatura de aproximadamente $1.040{ }^{\circ} \mathrm{C}$ e possuem capacidade de queimar 30.000 tijolos semanalmente. Após a etapa da queima, é aguardado o tempo de arrefecimento do forno, processo que dura cerca de 4 a 6 dias. Após este período, os tijolos são retirados com auxílio de um transportador manual e manejados para um local de armazenamento. Logo após, são embalados e despachados para o mercado consumidor.

\section{PROCEDIMENTOS METODOLÓGICOS}

Para obtenção de informações referentes aos principais aspectos e impactos ambientais na etapa de produção da atividade de cerâmica vermelha, foi realizado um levantamento bibliográfico em fontes de periódicos, tais como Google Scholar e Scientifc Library Eletronic Online (SciELO). Para a fase de produção, a identificação dos aspectos e impactos foi realizada a partir de visita in loco, com realização de anotações referentes às fases de produção destacadas anteriormente. De maneira complementar, foi aplicado um formulário semiestruturado contendo 15 questões relativas às práticas adotadas pelo empreendimento quanto a execução das etapas de produção, geração e manejo de resíduos sólidos e emissões de poluentes atmosféricos.

\section{RESULTADOS E DISCUSSÃO}

\section{ASPECTOS AMBIENTAIS NA FASE DE PRODUÇÃO}

A partir da visita in loco no empreendimento, no município de Paragominas, foi possível observar alguns aspectos ambientais relativos às etapas de produção de tijolos. Em todas as etapas foram identificados aspectos ambientais, sendo os mais comuns em algumas etapas, a emissão de ruído, consumo de água e de energia elétrica (Quadro 1).

Quadro 1 - aspectos ambientais identificados na fase de produção de tijolos

\begin{tabular}{|l|l|}
\hline Etapas de produção & Aspectos ambientais \\
\hline Caixão alimentador & Emissão de ruídos, Consumo de água e energia elétrica. \\
\hline Mistura & $\begin{array}{l}\text { Consumo de água e energia elétrica e resíduo de óleo } \\
\text { lubrificante }\end{array}$ \\
\hline Maromba & $\begin{array}{l}\text { Emissão de ruído, resíduo de óleo lubrificante e consumo } \\
\text { de energia elétrica. }\end{array}$ \\
\hline Corte & Geração de resíduos e consumo de energia elétrica. \\
\hline Queima & $\begin{array}{l}\text { Emissão de poluentes atmosféricos, ruído e geração de } \\
\text { resíduos de queima. }\end{array}$ \\
\hline
\end{tabular}

Fonte: autores (2018). 
Durante a fase de produção, a emissão de ruídos configura-se como uma das principais problemáticas da atividade de cerâmica vermelha, provocada pelo funcionamento do maquinário. As emissões ocorrem em várias etapas do processo de produção de cerâmica vermelha, sendo mais intensas nas etapas de moagem, mistura e prensagem, e nas atividades de transporte de veículos e máquinas, tanto de materiais como de produtos acabados e resíduos (SANTOS; JACOME, 2017). Tais fatores foram observados no empreendimento analisado, principalmente na utilização do maquinário, que fica em funcionamento durante aproximadamente 12 horas.

O ruído afeta principalmente as atividades desenvolvidas no ambiente laboral, e quando caracterizado de forma excessiva torna-se fator influente da poluição sonora, sendo este um dos impactos ambientais oriundos das fases de produção de tijolos. O ruído é intensificado na área pela ausência de proteção das máquinas (abafadores), o que compromete o desenvolvimento das atividades de maneira totalmente segura. Os ruídos intensos em atividade de cerâmica vermelha tendem a prejudicar tarefas que exigem concentração mental ou que requerem maior atenção, velocidade e precisão dos movimentos e os resultados tendem a piorar após 2 horas de exposição ao risco. O ruído também produz o aborrecimento, devido a uma interrupção forçada das tarefas (SILVA; SOUSA JÚNIOR, 2015).

Quanto ao consumo de água, verificou-se que este é um componente de grande importância no processo produtivo, utilizado principalmente na etapa de mistura (Figura 2). A água utilizada no processo de produção é extraída de "poços artesianos" localizados na área do empreendimento.

Figura 2 - utilização de água na etapa de mistura na fase de produção de tijolos, Paragominas - PA.

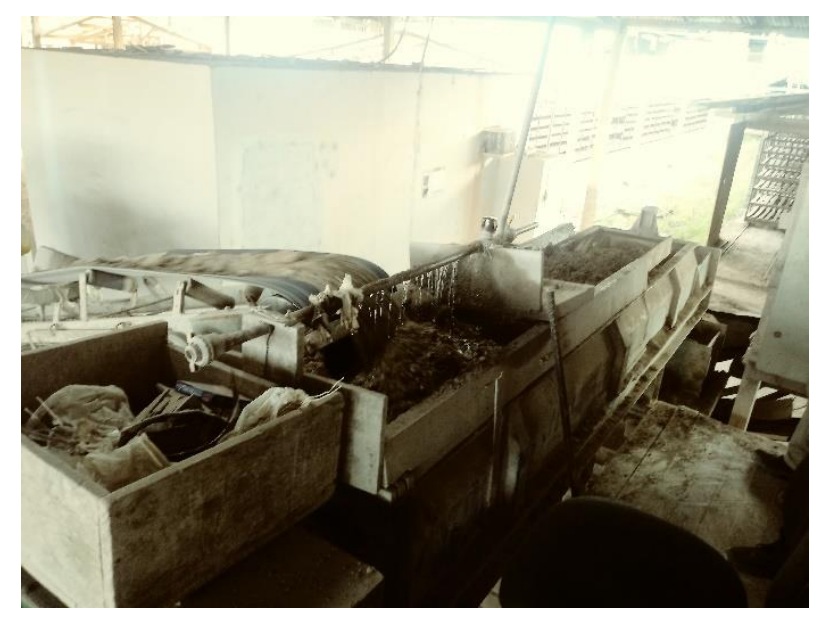

Fonte: autores (2018).

Nesse tipo de empreendimento, foi verificado altos consumos de:

1) Água, pois, em atividade ceramista é um fator que necessita de maiores avaliações, haja vista que o excessivo uso deste recurso natural pode contribuir para agravamento de maiores complexidades ambientais, como empobrecimento de lençóis freáticos, o que provoca desequilíbrios no ciclo hidrológico e indisponibilidade de água para abastecimento humano.

2) Energia elétrica, devido ao funcionamento das máquinas (MANFREDINI, 2003). Este fator foi confirmado no empreendimento analisado, onde de acordo com o responsável geral pelas atividades, o consumo representa custo considerável para empresa. Em pesquisa realizada por Araújo e Brito (2015), na cidade de Monteiro -PB, os autores verificaram que a atividade de cerâmica vermelha é responsável por alto consumo de água (43.000 litros/mês) e energia (30.509 KW/h/mês), relacionados com a alta produtividade do empreendimento pesquisado. Logo, esses insumos são aspectos ambientais que estão relacionados, de maneira indireta, com a perda de biodiversidade regional, fator este, atrelado, principalmente com a hidroeletricidade.

A emissão de poluentes atmosféricos foi verificada durante a fase de transporte de material (queima de combustíveis fósseis) e durante a fase de queima dos tijolos (queima de pó de serragem). 
Elas configuram-se em um aspecto ambiental influente nela, seja local ou regional, intensificada pela ausência de filtros nos fornos e pela altitude reduzida das chaminés (Figura 3).

Figura 3 - vista frontal da chaminé no empreendimento analisado. Paragominas - PA.

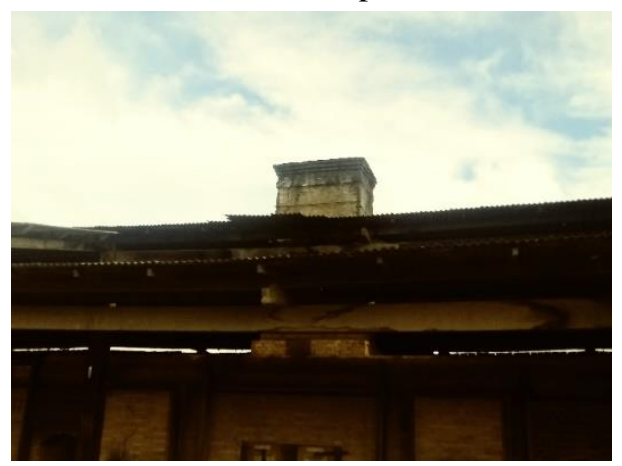

Fonte: Fonte: autores (2018).

Em indústria de cerâmica vermelha verifica-se a emissão de uma quantidade significante de material particulado para a atmosfera. A emissão constante de gases e material particulado, intensificada pela ausência de filtros nas chaminés, representa um agravante da poluição atmosférica e consequentemente à saúde humana (CAMARA et al., 2015).

Quanto aos resíduos sólidos gerados na atividade de produção, foram verificados no empreendimento, principalmente cinzas oriundas da queima realizada nos fornos, restos de cerâmicas resultantes de quebra de telhas e tijolos durante produção e armazenamento do produto e tijolos defeituosos ou que não obtiveram padrão de qualidade desejável ao mercado. os resíduos são acondicionados de forma inadequada em uma pilha na área externa do espaço de produção e não é realizada frequentemente o transporte deste material para um local adequado, o que está associado de maneira direta e indireta com riscos à saúde humana e com a poluição atmosférica (Figura 4).

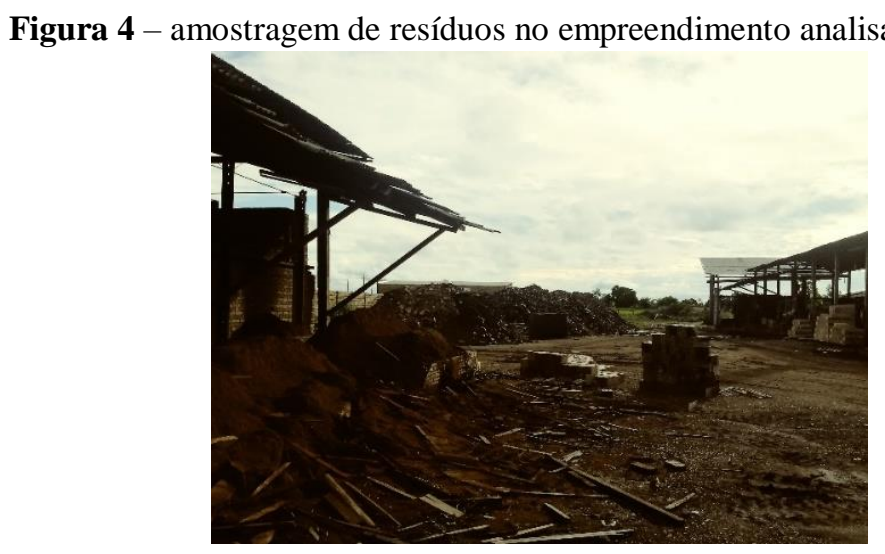

Fonte: autores (2018).

Em pesquisa realizada por Lucena (2007), foi verificado que a atividade de cerâmica vermelha é uma considerável geradora de resíduos sólidos, com produção de quantidades significativas diariamente.

Nas proximidades da área de produção de tijolos, foi observado extravasamento de óleo lubrificante (Figura 5a), utilizado para o processo de manutenção do maquinário. Além deste fator, há presença de tambores de armazenamento de óleo que, devido ao acondicionamento inadequado também provocam disseminação do conteúdo no solo (Figura 5 b). 
Figura 5 - a) presença de óleo lubrificante derramado em área próxima ao maquinário; b) tambores de armazenamento de óleo disposto inadequadamente. Paragominas - PA.

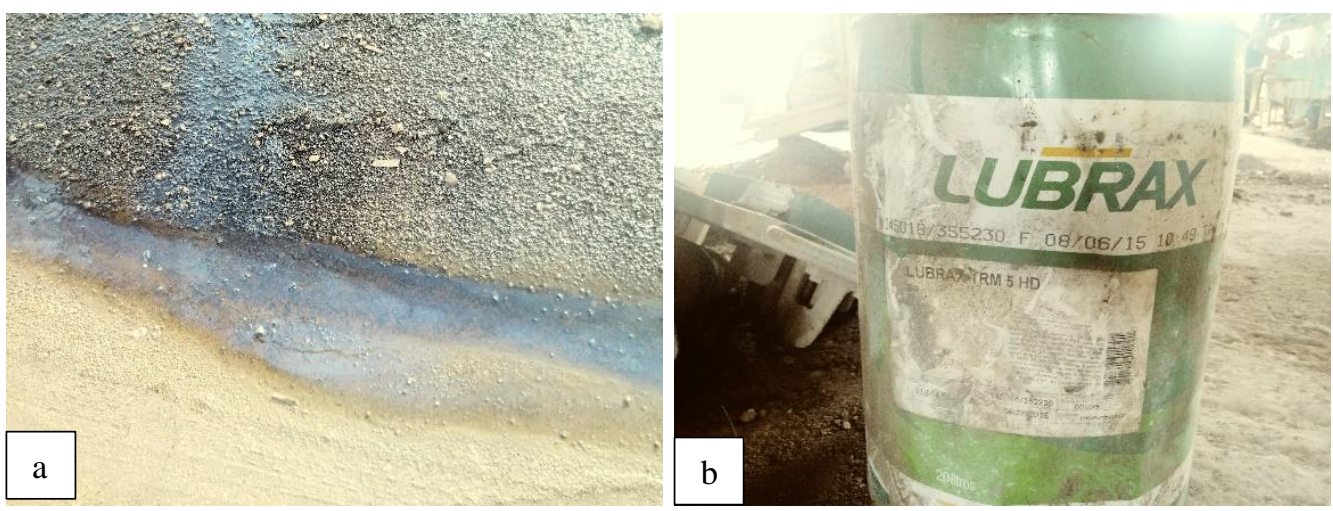

Fonte: autores (2018).

$\mathrm{Na}$ área compreendida pelo empreendimento há presença de uma oficina de manutenção e lavagem dos veículos utilizados para transporte de matéria-prima e produto final. Na mesma não é realizado nenhum tipo de tratamento do efluente gerado, ficando este em contato direto com o solo (Figura 6).

Figura 6 - área de lavagem de veículos com disposição inadequada de efluentes. Paragominas - PA.

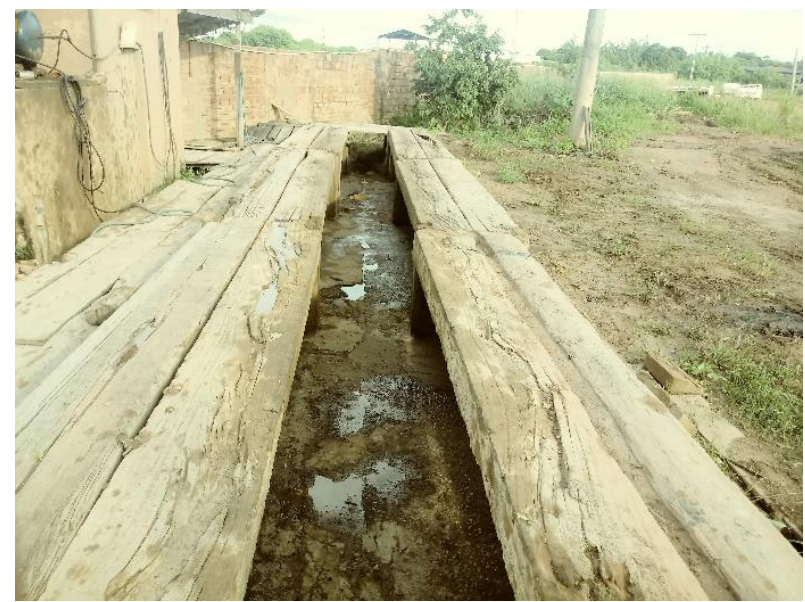

Fonte: autores (2018).

A disposição final das embalagens de óleo lubrificante e efluentes, caracterizada como inadequada, pode ocasionar problemáticas ambientais de caráter comprometedor, principalmente ao solo, haja vista que este encontra-se de maneira exposta na área correspondente ao empreendimento.

O efluente, sem nenhum tipo de tratamento, quando jogado na rede coletora de esgoto, diminui o rendimento do tratamento dos efluentes, aumentando a carga de poluentes lançada nos rios (GOMES; OLIVEIRA; NASCIMENTO, 2008). Tal problemática é intensificada negativamente devido à ausência de uma estação de tratamento de esgoto.

\section{MEDIDAS MITIGADORAS}

Em relação aos potenciais/possíveis impactos provocados nas etapas de produção dos tijolos, verifica-se que para a poluição sonora, pode-se realizar se considerar necessário, o processo de tratamento acústico de equipamentos ou das edificações, o que busca evitar a ocorrência de poluição sonora no ambiente. Tal tratamento pode ser realizado a partir da utilização de estruturas 
separadoras de ambientes, construídas com materiais capazes de proporcionar isolamento de ruídos (SANTOS NETO, 2006).

A problemática do alto consumo de água pode ser mitigada a partir da redução do consumo, após quantificação do necessário para a produção, ou investimento em tecnologias de reaproveitamento de água. O consumo de energia elétrica é uma problemática ambiental, que pode ser reduzida a partir de adoção de práticas sustentáveis de produção de energia, como investimento em painéis fotovoltaicos.

Além de tal fator, quando há utilização de exaustores, pode ser realizada a confecção de chaminés mais altas, para que assim os exaustores não sejam necessários, o que favorece a redução não apenas do consumo de energia, mas também da dependência da eletricidade oriunda da rede de distribuição para a realização de dispersão da fumaça gerada no processo (ARAÚJO; BRITO, 2015).

Para a problemática relacionada com a emissão de poluentes atmosféricos, pode ser executado o controle da emissão, a partir da fixação da altura adequada das chaminés e a instalação de equipamentos para depuração dos gases. As emissões de partículas podem ser controladas pelo uso de equipamentos de aspiração e separação mediante o uso de ciclones. A serragem deve ser armazenada em local coberto, evitando-se a dispersão de partículas pelo vento. Uma maneira de controlar as emissões de gases consiste no uso de sistemas de exaustão e captação dos gases e tratamento mediante o uso de lavadores de gases, ou absorção com carvão ativado entre outras técnicas (COSTA, 2013).

A utilização de resíduos como: pó de serragem, cavaco, bagaço de cana, sabugo de milho, palha de café, e outros representam alternativas para redução da emissão de gases causadores de efeito estufa durante o processo de queima. No empreendimento em análise, é utilizado como material para alimentação dos fornos o pó de serragem (Figura 7), o que evidencia amenização do passivo ambiental da empresa no que tange ao aspecto de emissão de componentes de característica poluidora.

Figura 7 - material utilizado para alimentação dos fornos de queima. Paragominas - PA.

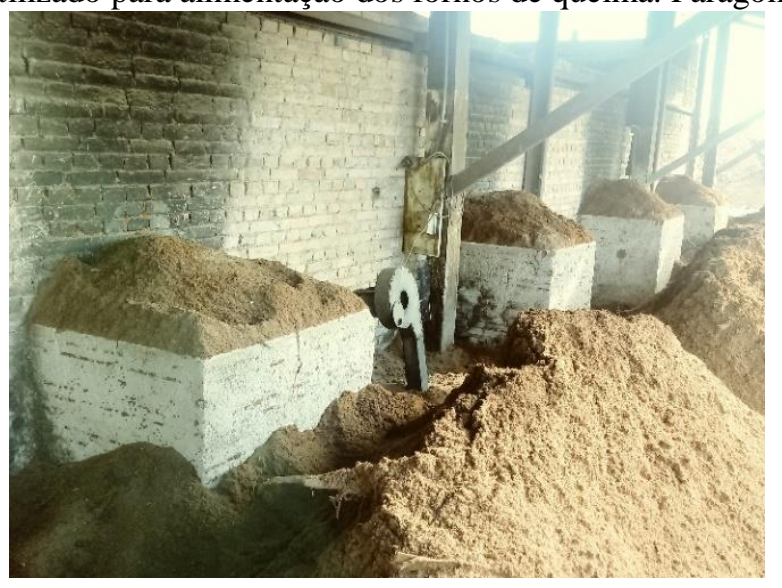

Fonte: autores (2018).

Como formas de mitigação dos impactos provocados pela geração de resíduos sólidos durante a atividade, pode ser realizada a utilização das cinzas como adubo para aplicação em áreas de cultura florestal, cuja cadeia gera resíduos aproveitáveis nos fornos de queima de tijolos e telhas. Os materiais danificados no processo de armazenamento ou que se encontram fora do padrão de venda para o mercado podem ser recolhidos para doação a instituições beneficentes ou associações de moradores, haja vista que são aproveitáveis (CUNHA; SIQUEIRA, 2013).

O derramamento de óleo na área de produção pode ser resolvido a partir do cumprimento dos requisitos mínimos estabelecidos na resolução do Conselho Nacional do Meio Ambiente (CONAMA), n. 362, de 23 de junho de 2005. Esta, estabelece que óleo o lubrificante usado ou contaminado deve obrigatoriamente ser recolhido e ter destinação adequada, de forma a não afetar 
negativamente o meio ambiente, e proíbe quaisquer descartes em solos, águas subterrâneas, no mar e em sistemas de esgoto ou evacuação de águas residuais.

Para cumprimento do estabelecido pela resolução, o empreendimento pode realizar o repasse das embalagens de lubrificante e o óleo queimado para empresas especializadas na logística reversa desses resíduos, ou definir com o fornecedor do produto a devolução do material.

\section{CONCLUSÕES}

Para a etapa de produção de tijolos, os principais aspectos ambientais identificados no empreendimento em estudo estão relacionados com as etapas maromba e queima, nas quais se verifica emissões constantes de ruído e de partículas poluidoras, respectivamente. Nessa vertente, a contribuição para o agravamento da problemática de poluição atmosférica caracteriza-se como a mais significativa.

Diversas medidas podem ser adotadas para mitigação das problemáticas ambientais relacionadas com as atividades de cerâmica vermelha, as quais podem ser realizadas a partir do cumprimento de normas regulamentadoras e legislação além de ações de manutenção periódica de estrutura e equipamentos.

\section{REFERÊNCIAS}

ARAÚJO, D. T. R.; BRITO, W. O. Avaliação do ciclo de vida na fabricação de tijolos cerâmicos na cidade de Monteiro-PB. In: Congresso Brasileiro de Gestão Ambiental, 6,2015. Anais...Porto Alegre: IBEAS, 2015, p. 1-5.

BRASIL, A. P. Diagnóstico Socioeconômico e Florestal do município de Paragominas. Belém: Imazon, 2009.

CAMARA, V. F. et al. Levantamento das emissões atmosféricas da indústria da cerâmica vermelha no sul do estado de Santa Catarina, Brasil. Cerâmica, São Paulo, v. 61, n. 358, p.213-218, jun. 2015.

CONAMA. CONSELHO NACIONAL DO MEIO AMBIENTE. Resolução no 362, de 23 de junho de 2005. Dispõe sobre o Recolhimento, Coleta e destinação de óleo lubrificante usado ou contaminado. Disponível em: <http://www.mma.gov.br/port/conama/legislacao/2005_362>. Acesso em: 15 fev. 2018.

COSTA, M. A. A. Impactos Socioambientais e Medidas Atenuantes de uma Empresa de Cerâmica Vermelha, Itajá/RN: Estudo Preliminar. 2013. 57 f. Monografia (Graduação). Curso de Ciência e Tecnologia. Universidade Federal Rural do Semiárido, Angicos, 2013.

CUNHA, L. C. C.; SIQUEIRA, R. A. C. de. Gestão de Qualidade de Resíduos Sólidos em uma cerâmica em Timon - MA. In: iv congresso brasileiro de gestão ambiental, 4., 2013, Salvador. ConGeA. Salvador: Ibeas, 2013. p. 01 - 10, 2013.

GOMES, P. L.; OLIVEIRA, V. B. P.; NASCIMENTO, E. A. Aspectos e impactos no descarte de óleos lubrificantes: o caso das oficinas. In: CONGRESSO NACIONAL DE EXCELÊNCIA EM GESTÃO, 4., 2008, Niterói. Anais... Niterói: Cneg, 2008. p. 1 - 15.

HENTZ, A. M. Projeto de reabilitação de áreas degradadas através da produção das mudas de espécies florestais nativas inoculadas com fungos micorrízicos arbusculares. Convênio UFPA e Sindicato das Cerâmicas Vermelhas de Marabá-PA. 2012. 
KUASOSKI, M.; DOLIVEIRA, S. L. D.; SILVA, A. Q. Impactos socioambientais no processo de extração e transporte da argila em indústrias de cerâmica vermelha. Sustentabilidade e responsabilidade social, p. 92, 2015.

LEITE, J. F. et al. Análise do layout do processo de fabricação de tijolos: um estudo de caso para melhoria da produtividade e da segurança e saúde dos funcionários. 2016. Enegep. Disponível em: <http://www.abepro.org.br/biblioteca/TN_STP_226_323_29329.pdf>. Acesso em: 02 set. 2018.

LUCENA, M. M. Efeito de introdução de resíduo de cinza de forno cerâmico em massa para cerâmica estrutural. 2007. Dissertação (Mestrado em Engenharia Mecânica). Universidade Federal do Rio Grande do Norte, Natal, 2007.

MANFREDINI, C. Impactos Ambientais causados pelas indústrias de cerâmica vermelha no Rio Grande do Sul. 2003. Dissertação (Mestrado em Engenharia Civil). Universidade Federal do Rio Grande do Sul, Porto Alegre, 2003.

MELLO, A. H. Diagnóstico da degradação ambiental em áreas de extração de argila em MARABÁ - PA. Revista Agroecossistemas, Belém, v. 9, n. 1, p. 45-61, out. 2017.

NUNES, M.B. Impactos ambientais na indústria da cerâmica vermelha. Relatório Técnico. Rede de Tecnologia e Inovação- REDETEC, Rio de Janeiro, 2012.

OLIVEIRA, M.C.; MAGANHA, M. F. B. Guia técnico ambiental da indústria de cerâmicas brancas e de revestimento. São Paulo: CETESB, 2006.

SANTANA, A. et al. Cerâmica vermelha. Serviço Brasileiro de Apoio às Micro e Pequenas Empresas - SEBRAE: São Paulo, 2008.

SANTOS JUNIOR, E. L. et al. Avaliação de Impacto Ambiental da Indústria Cerâmica Estrutural como Ferramenta da Produção Mais Limpa. In: INTERNATIONAL WORKSHOP ADVANCES IN CLEANER PRODUCTION, 6., 2017, São Paulo. Anais... São Paulo: Advancesincleanerproduction, 2017. p. 1 - 9.

SANTOS NETO, N. A. Caracterização do isolamento acústico de uma parede de alvenaria estrutural de blocos cerâmicos. 2006. Dissertação (Mestrado em Engenharia Civil). Universidade Federal de Santa Maria, Santa Maria, 2006.

SANTOS, D. D. S.; JACOME, P. C. Levantamento e análise dos riscos presentes em uma cerâmica vermelha situada no vale do Açu. In: Encontro Nacional de Engenharia de Produção, 37., 2017. Anais...Joinville: Abepro, 2017. p. 241-399.

SILVA, F.; SANTOS, M. Aspectos ambientais da extração de argila em áreas de planície fluvial do baixo Jaguaribe - CE. Revista Geonorte, Manaus, v. 4, n. 1, p.135-140, jun. 2014.

SILVA, M. M. N.; SOUSA JÚNIOR, A. M. Análise qualitativa dos riscos ocupacionais da atividade ceramista na cidade de encanto/RN. In: ENCONTRO NACIONAL DE ENGENHARIA DE PRODUÇÃO, 35., 2015, Fortaleza. Anais...Fortaleza: Abepro, 2015. p. 1 - 11. 
SOUZA, V. P. et al. Análise dos gases poluentes liberados durante a queima de cerâmica vermelha incorporada com lodo de estação de tratamento de água. Cerâmica, São Paulo, v. 54, n. 331, p. 351355, set. 2008.

VALE, S. A., et al. A Minimização dos Impactos Ambientais Causados pela Produção de Cerâmica Vermelha com Utilização da Análise Racional para Formulações de Massa. Cerâmica Industrial, São Paulo, v. 11, n. 2, p. 39-41, set./dez. 2006.

\section{Lucimar Costa Pereira}

Concluinte do curso de Engenharia Ambiental

Universidade do Estado do Pará

Departamento de Engenharia Ambiental lu.costa0708@gmail.com

Maria Renata da Rocha Xavier

Concluinte do curso de Engenharia Ambiental

Universidade do Estado do Pará

Departamento de Engenharia Ambiental renatarochax@hotmail.com

Maycon Viana Balbino Concluinte do curso de Engenharia Ambiental

Universidade do Estado do Pará

Departamento de Engenharia Ambiental maykon.lbino@gmail.com

Nayara do Socorro Nascimento Farias Concluinte do curso de Engenharia Ambiental

Universidade do Estado do Pará

Departamento de Engenharia Ambiental nayarafarias@outlook.com

Lorena Saraiva Viana

Concluinte do curso de Engenharia Ambiental

Universidade do Estado do Pará

Departamento de Engenharia Ambiental lorenaengamb20@gmail.com

Tulio Marcus Lima da Silva. Engenheiro Ambiental

Universidade do Estado do Pará Departamento de Engenharia Ambiental tuliosilva@id.uff.br 